RESEARCH AND PRACTICE

\title{
Use of geographical information systems to identify counties in Georgia with high risk for childhood lead poisoning
}

\author{
R. Christopher Rustin, DrPH, MT, REHS ${ }^{1}$, Christy Kuriatnyk, MSPH, REHS ${ }^{1}$, Byron Lobsinger, BS, GACEM ${ }^{1}$, and Simone \\ Charles, $\mathrm{PhD}, \mathrm{MS}^{2}$
}

${ }^{1}$ Environmental Health Section, Georgia Department of Public Health, Atlanta, GA; ${ }^{2}$ Division of Public Health and Department of Family Medicine, College of Human Medicine, Michigan State University, Flint, MI

\begin{abstract}
Background: For children in Georgia, lead poisoning is a substantial public health problem. Primary risk factors include low socioeconomic status and poor-quality housing built prior to 1978. The Environmental Health Team of the Georgia Department of Public Health (DPH) utilized geographical information system (GIS) technology and census housing data to identify counties in which children have high risk for lead poisoning. The purpose of this research was to update and refine previous maps developed with older technology and on a different geographic scale so that targeted public health interventions can be developed.
\end{abstract}

Methods: Data related to stratified and median housing age data were derived from the 2013 5-year American Community Survey. With ESRI ArcMap 10.2 geographic information software, the data were geospatially linked to the state's county shapefile for development of spatial maps.

Results: A series of spatial maps were developed utilizing housing risk factors of age and occupancy status. Refined spatial maps were developed for: 1) the percentage of homes built prior to 1978 and prior to 1950 per county; 2) owner- and renteroccupied housing stratified by age and color-coded per county; and 3) counties in which children were at high risk for lead poisoning.

Conclusions: The data from this research provides information for the DPH Lead and Healthy Homes program of areas in the state where targeted interventions are needed. The updated maps can be used to educate policy makers, healthcare providers, and community leaders in regard to prevention of lead poisoning.

Keywords: childhood lead poisoning, risk factors, GIS, lead poisoning prevention

\section{INTRODUCTION}

Childhood lead poisoning is a substantial public health problem nationally and especially for children in Georgia. Primary risk factors include lower socioeconomic status, residing in poor- quality housing built before 1978 (the year residential lead paint was banned), and normal hand-mouth behaviors of children that allow ingestion of chipped paint and lead dust [Centers for Disease Control and Prevention (CDC), 2015; Koller et al., 2004]. For young children ( $\leq 6$ years of age), lead poisoning is particularly hazardous due to their developing brain, organs, and faster metabolism. It has the potential to cause a reduction in I.Q., learning and cognitive disabilities, behavioral problems, seizures, colic, coma, and even death (Canfield, et al., 2003; CDC, 2008; Binns, Cambell, \& Brown, 2007; Miranda et al., 2007; Needleman et al., 2002). Although no safe threshold for lead has been identified, the CDC, in 2012, established a blood lead reference level of $\geq 5$ micrograms per deciliter $(\mu \mathrm{g} / \mathrm{dL})$; at which public health action is recommended (CDC, 2015). This value is updated every four years, based on the 97.5 percentile of blood lead levels of children aged 1-5, as determined by the National Health and Nutrition Examination Survey (NHANES).

\section{Background}

Since 1994, the mission of the Lead and Healthy program of the Georgia Department of Public Health (DPH) has been to eliminate childhood lead poisoning in Georgia (DPH, 2015). This is achieved through surveillance, collaboration with healthcare providers, education, inspections, and enforcement of laws regarding lead for homes built prior to 1978. DPH case management guidelines indicate that children are to be tested for lead at 12 and 24 months of age or between 36-72 months of age if no previous test was conducted. Laboratories and physicians report all blood lead levels to DPH as a mandated notifiable disease, thus allowing passive surveillance. Annually, laboratories and physicians report over 100,000 blood lead results to the DPH with $>3,000$ of these exceeding the CDC reference blood lead level of $\geq 5 \mu \mathrm{g} / \mathrm{dL}$ and for all children with a confirmed blood lead level of $\geq 10 \mu \mathrm{g} / \mathrm{dL}$, a home environmental investigation is conducted by a DPHcertified Lead Inspector/Risk Assessor. With limited public 
health staff, this ensures that children with the highest need are prioritized.

\section{Purpose: Updated Housing Risk Maps}

Although children can be exposed to lead via imported toys or foods, primary exposure is associated with living in or visiting homes built prior to 1978 (Landrigan et al., 2010; Rauh et al., 2008; CDC, 1998). The Consumer Product Safety Commission banned residential lead paint in 1978. All homes built prior to 1978 have a risk for lead exposure, but homes built before 1950 carry a higher risk due to high content of lead used in paint before that time (Markowitz \& Rosner, 2000; Rabin, 1989). A primary prevention goal of the DPH is to prevent children from being exposed to lead in the home. This requires targeting the location of pre-1978 housing in Georgia so that public health interventions can be implemented. In Georgia, there are approximately 4,094,812 housing units with an estimated 1,548,796 (38\%) built prior to 1978 and 578,867 (14\%) built prior to 1950 (Census, 2013). To identify locations of high-risk housing, the DPH Environmental Health team reviewed an existing lead poisoning prevention map and determined that the map needed updating due to its simplicity, limited geographic scale, and lack of detail. By use of geographical information system (GIS) technology combined with census data on housing and blood lead surveillance, new spatial maps were created to identify the counties in which children are at a high risk for lead poisoning. For all counties, these updated maps targeted the type (owner or renter) and location of pre1978/pre- 1950 housing, thus allowing the DPH to target prevention activities on a more refined scale.

\section{METHODS}

In 2014, the Georgia DPH was awarded a three-year Lead Poisoning Prevention Surveillance grant from the CDC. The purpose of this grant was to build the state's capacity for lead surveillance to aid in prevention and ultimate elimination of childhood lead poisoning. Since housing is the primary source of lead exposure, prevention and elimination of lead poisoning requires spatial knowledge of where children are being exposed to lead. The DPH Environmental Health team analyzed existing GIS maps to determine if they were useful at targeting lead risk. The existing map (Figure 1.0) was developed in 2005 and displayed only counties that were considered high risk based on surveillance screening data for children with blood lead levels $\geq 10 \mu \mathrm{g} / \mathrm{dL}$.
Figure 1.0- Georgia High Risk Counties

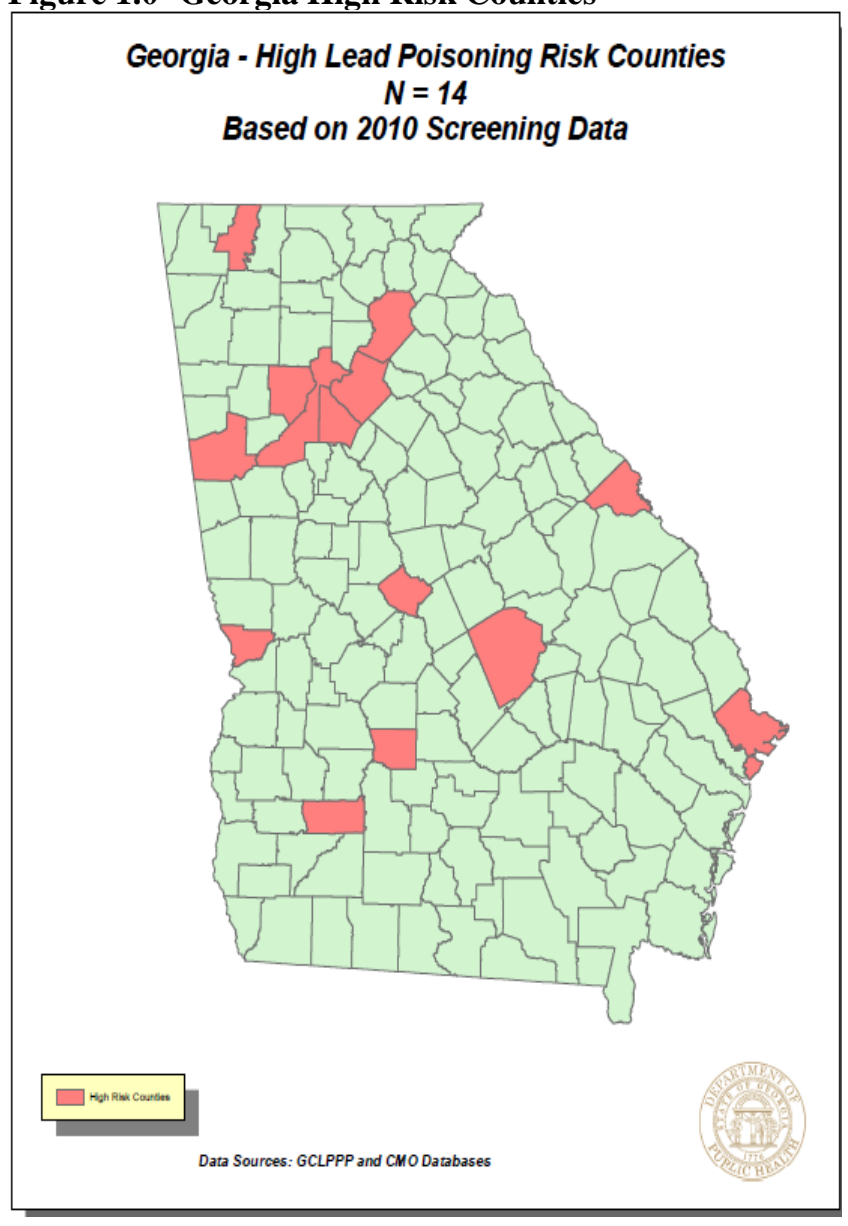

The map identified counties in which children had elevated blood lead levels $(\geq 10 \mu \mathrm{g} / \mathrm{dL})$ at the time. There were, however, no spatial elements that stratified the locations of older housing and no indication of the percent of older housing within those counties. Further, when the map was constructed, children exposed to lower levels of lead $(\geq 5 \mu \mathrm{g} / \mathrm{dL})$ were not a priority.

\section{Development of New Risk Maps}

To develop a series of new risk maps at different geographic scales, DPH staff utilized housing data in the U.S. Census Bureau's 2013 5-year American Community Survey (ACS). These data reached to the level of the county and census block groups for median and stratified housing age. In addition, the ACS contained the number of Georgia housing units stratified by age group in 10-year blocks beginning in 1939 or earlier and including the overall percentage of each age group with a standard margin of error for each county. This is demonstrated in Table 1. 
Table 1. Stratified Age of Housing in Georgia (Census, 2013)

\begin{tabular}{|c|c|c|c|c|}
\hline YEAR BUILT & \# of Housing Units & Margin Error & $\%$ & \% Margins of Error \\
\hline Total housing units & $4,094,812$ & $+/-551$ & $4,094,812$ & $(\mathrm{X})$ \\
\hline Built 2010 or later & 25,355 & $+/-1,173$ & $0.60 \%$ & $+/-0.1$ \\
\hline Built 2000 to 2009 & 937,248 & $+/-6,310$ & $22.90 \%$ & $+/-0.2$ \\
\hline Built 1990 to 1999 & 862,395 & $+/-6,587$ & $21.10 \%$ & $+/-0.2$ \\
\hline Built 1980 to 1989 & 721,018 & $+/-5,170$ & $17.60 \%$ & $+/-0.1$ \\
\hline Built 1970 to 1979 & 592,895 & $+/-5,951$ & $14.50 \%$ & $+/-0.1$ \\
\hline Built 1960 to 1969 & 377,034 & $+/-4,658$ & $9.20 \%$ & $+/-0.1$ \\
\hline Built 1950 to 1959 & 264,474 & $+/-3,616$ & $6.50 \%$ & $+/-0.1$ \\
\hline Built 1940 to 1949 & 124,120 & $+/-2,312$ & $3.00 \%$ & $+/-0.1$ \\
\hline Built 1939 or earlier & 190,273 & $+/-2,591$ & $4.60 \%$ & $+/-0.1$ \\
\hline
\end{tabular}

Census, 2013

For the first series of maps, data related to stratified housing age for each county were exported into an Excel spreadsheet and imported into ESRI's ArcMap GIS version 10.2 software. The data were collated and evaluated statistically by county, public health district, political boundaries, or as spatially needed for lead poisoning risk. The data were then geospatially linked to the state's county shapefile to create two choropleth, color-coded risk maps that demonstrated the percentage of housing built in each county prior to 1980 and that prior to 1950 .

A second series of maps was developed to identify the locations of high-risk housing within counties. Data related to median age of housing block groups were extracted from the 2013 ACS and exported to an Excel spreadsheet. Data headers for the age of housing were formatted by blockgroup, geography, median year built, occupancy status year built, and margins of error; imported into ESRI's ArcMap GIS software and geospatially linked to the state's Census block group shapefile. Choropleth maps were constructed using the symbology classification tools within ArcMap GIS, thus creating maps with age, type, and location of housing, color-coded by pre 1951, 1951-1978, and post-1978 for owner-occupied and renter-occupied housing.

For the final map, blood lead surveillance data were analyzed for years 1998-2013 with a focus on the prevalence of elevated blood levels $(\geq 5 \mu \mathrm{g} / \mathrm{dL})$. The location of prevalence data and a geospatial review of the choropleth maps identified the counties in which these children were at high risk of lead poisoning. Within ArcMap GIS, the counties in which children are higher risk were selected interactively, creating a single category layer symbolically color-coded in red, overlaid onto to the Georgia county map. This updated the county map for lead poisoning shown in Figure 1.

\section{RESULTS}

Utilizing Census data and ArcMap GIS technology, the DPH Environmental Health team developed a series of spatial choropleth maps using risk factor variables of housing age, occupancy status, and data on elevated blood levels. The series of maps was created to demonstrate spatially the percentage of housing per county built before 1980 and before 1950 and the percentage of owner- and renter-occupied housing by the age of housing and to illustrate counties with children having elevated blood lead levels $(\geq 5 \mu \mathrm{g} / \mathrm{dL})$. This was accomplished to identify the counties in which children had a high risk for lead poisoning.

Percentage of Housing Pre-1980 and Pre-1950 by County In Figure 2, the percent of housing built before 1980 and before 1950 are demonstrated for each county. These maps show an escalating percentage increase of older housing via a ramped color scale with the counties shaded red containing a high percentage of pre-1980 and pre- 1950 housing units. For quick reference, the estimated percentage of housing age was written on each of the 159 counties for those built before 1980 . 
Figure 2. Percent Age of Housing by County

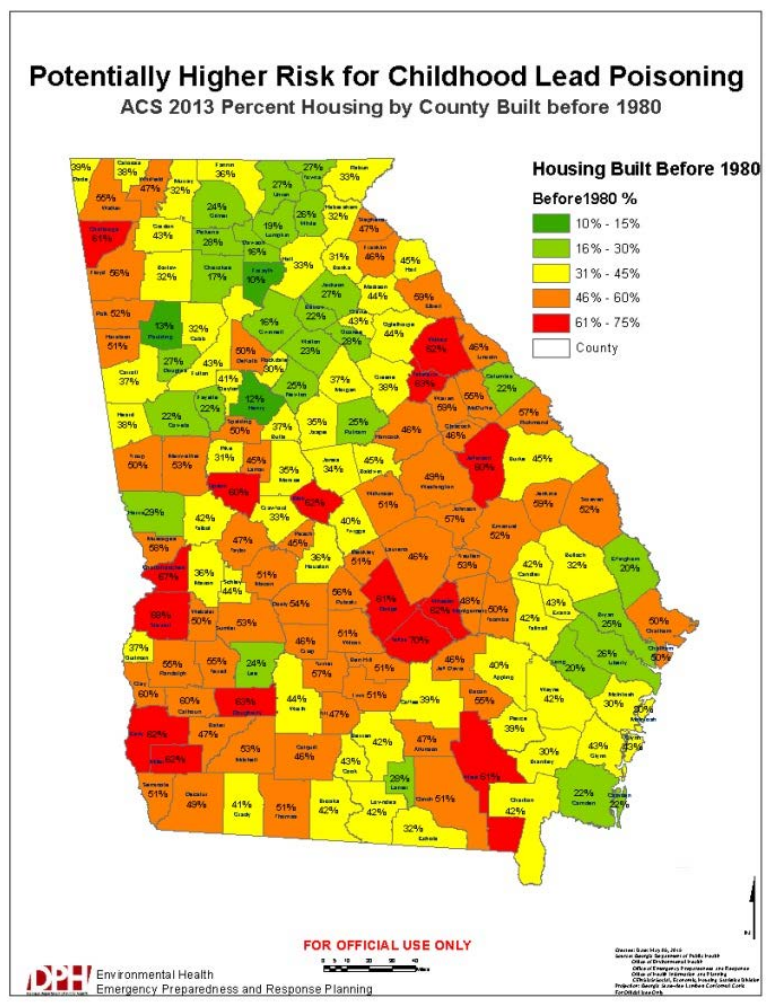

Stratified Age of Owner- and Renter-Occupied

In Figure 3, census block groups are color-shaded within each county and stratified to show the percentages and locations of owner- and renter-occupied housing. This stratification used a color-coded scheme of escalating increased risk from green (post- 1979), to yellow (1951-

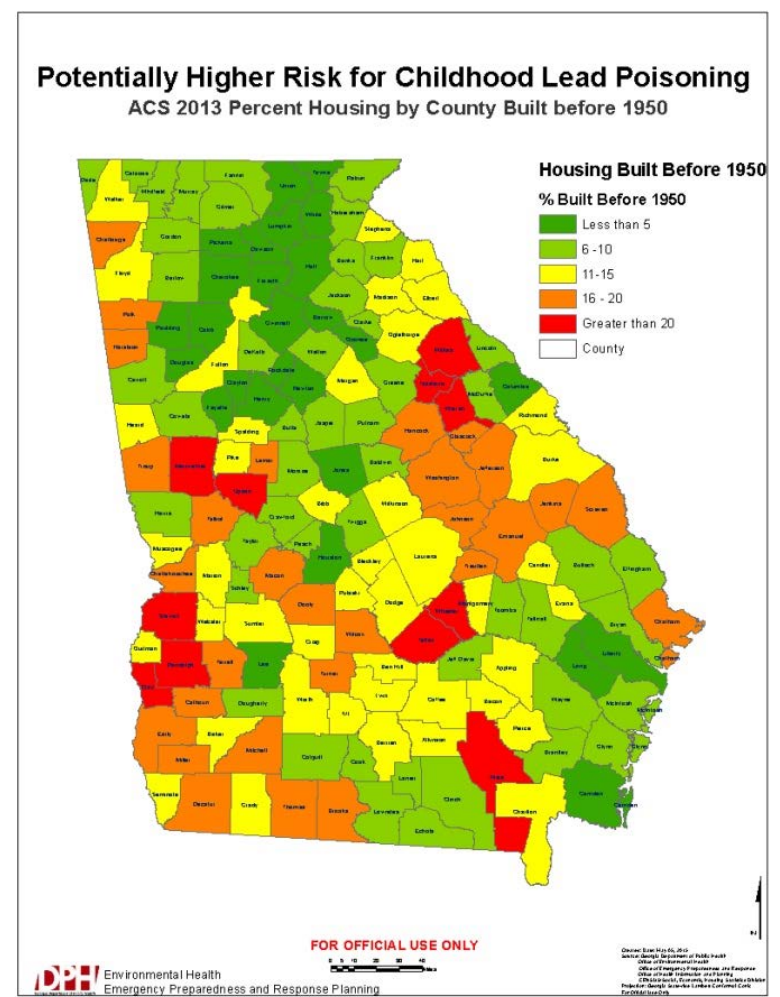

1978), to red (pre- 1951). Grey areas void of color indicate a lack of block group census data available for mapping. This series of maps demonstrates a more refined scale of housing age and location within each county and shows a clearer picture of lead poisoning risk across the state of Georgia by age, location, and the occupancy type of housing.

\section{Figure 3. Stratified Age of Owner and Rental Occupied Housing}
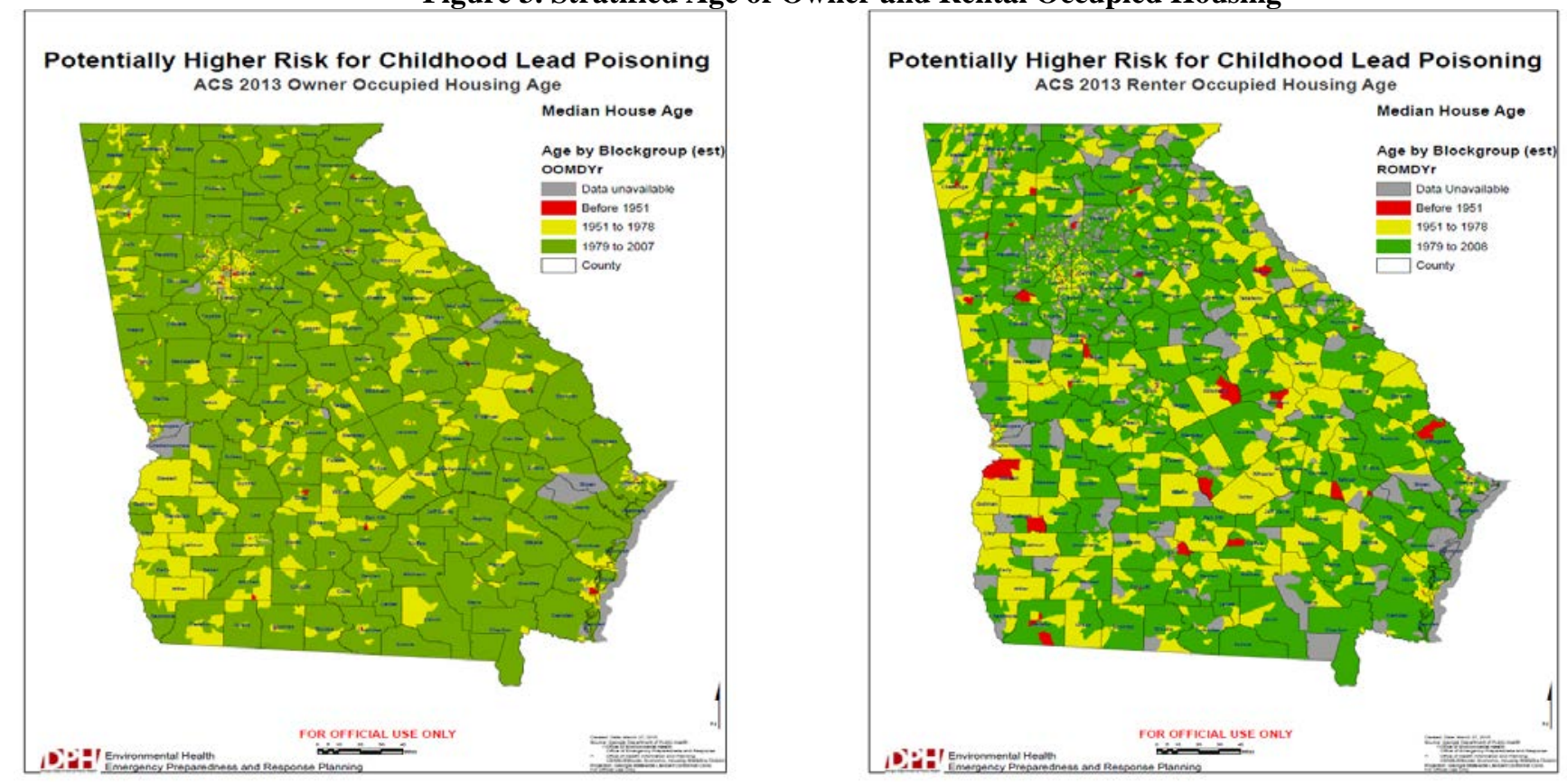
High-Risk Counties for Lead Poisoning

Analysis of high-risk areas in the previous spatial maps and analysis of historic blood lead surveillance data allowed the map shown in Figure 1 to be updated with the map shown in Figure 4. The current map highlights the counties with children at high risk for lead poisoning, as demonstrated by those color-coded red. A comparison of maps in Figures 1 and 4 shows a slight shift in counties considered to be at high-risk.

\section{Figure 4. High Risk Counties for Lead Poisoning}

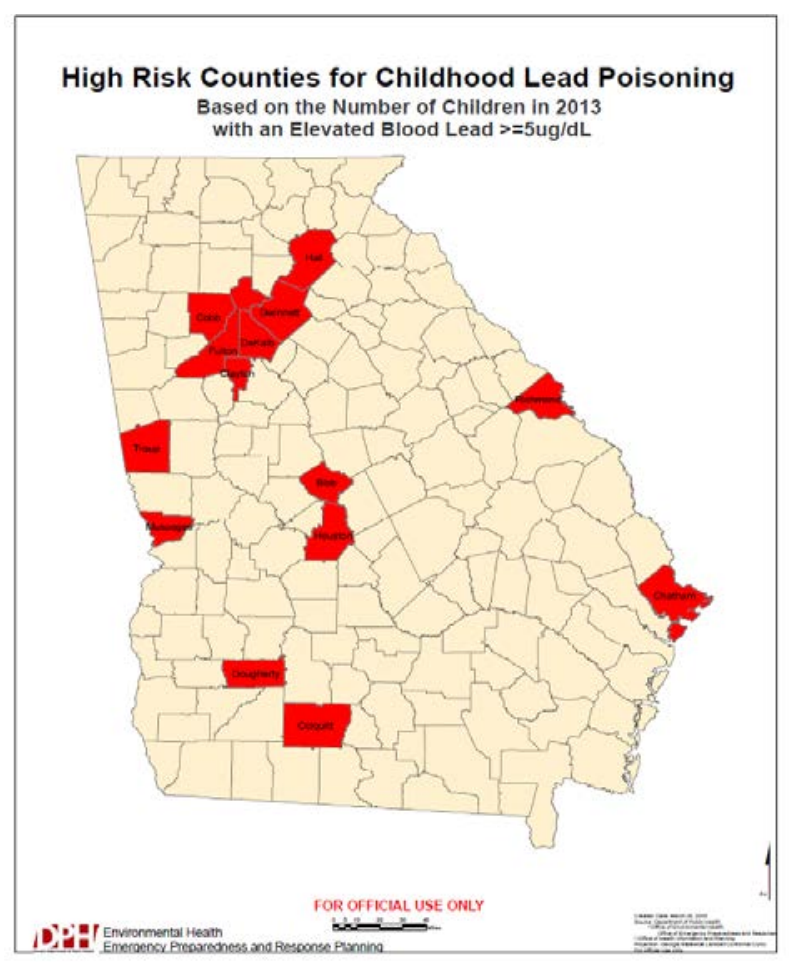

\section{DISCUSSION}

For children in Georgia, the risk for lead poisoning is high in large urban counties with densely-clustered older housing with a high population of children and in rural areas with older housing spread across counties and lower numbers of children at risk. Each area of the state has challenges in reducing lead exposures, but the first step to prioritizing public health interventions that have a strong geographical component is to determine locations where the risk of lead poisoning is high. This series of updated maps allows the DPH to visualize spatially and to target public health interventions in the counties in which children are at high risk.

The first series of spatial maps shows that the risk of lead poisoning is higher in counties with a higher percentage of homes built prior to 1950. These maps allow the DPH to link blood lead exposures with the risk level of each county and to identify high-risk counties where children should be prioritized for testing. With these data, the DPH can plan, prioritize and tailor public health interventions such as targeted education in the high-risk counties in which there are large numbers of children under the age of six.
The second series of maps shows the stratified risk for lead poisoning in homes built before 1978 with home occupancy type and the location of the high-risk neighborhoods; lowvalue pre-1950 rental homes clustered in urban areas (Lanphear et al., 2005; Farr \& Dolbeare, 1996). With these, to target improvements in lead testing, community outreach, and housing code enforcement, the DPH can analyze the locations of high-risk homes in comparison to where children are being exposed. Additional map layers can be created to show the relationships and locations between pediatrician offices and high-risk neighborhoods so that targeted outreach and education to the medical community can be provided, which can make physicians more aware of the problem of lead poisoning.

The last map created was an update of the high-risk counties as demonstrated by the number of children in 2013 with a blood lead reference level $\geq 5 \mu \mathrm{g} / \mathrm{dL}$, adding to the previous map's age of housing geospatial data for potential high-risk counties. As compared to the existing map in figure 1.0, further analysis in the shift of counties at high risk is a result of utilizing more advanced geospatial software and better census data and focusing on children with a blood lead reference level of $\geq 5 \mu \mathrm{g} / \mathrm{dL}$ versus $\geq 10 \mu \mathrm{g} / \mathrm{dL}$ in the older map. The shift in counties may also be attributed to the continued efforts of the Lead and Healthy Homes Program in educating the public and parents of children with the greatest potential for lead poisoning.

\section{Limitations}

A potential limitation is that Figure 2 shows calculated risk across counties. This does not take into account large urban inner cities which typically have higher populations of children at risk and a higher percentage of older housing clustered close together, thus increasing the chance of children being exposed to lead (Dignam et al., 2003). The DPH is currently constructing additional spatial maps that will focus on high-risk housing in the large urban cities of Georgia so that this risk can be characterized. Additionally, the second series of maps in Figure 3 has block group data missing for renter-occupied housing, for data were unavailable in the census. These missing data are primarily for rural areas of the state, but the deficiency limits the ability of the DPH to target high-risk rural areas that have characteristic challenges. Nevertheless, these maps will enhance the ability of the DPH to develop prevention activities.

\section{Implications for Public Health}

GIS, an information system for the “...input, storage, processing, and retrieving of spatial data...” (Bell et al., 2006), allows integration of data in a spatial picture that is easy to interpret, to identify trends, and to present to the public, which is relevant to public health programs (Kurland \& Wilpen, 2009). Spatial technology allows analysis and identification of health trends, mapping of environmental health issues, and ultimately development of public health interventions (Jerret, et al., 2010; Hopfer et al., 2008; Peng, 2001). Lead poisoning is appropriate for utilization of GIS spatial technology because there is a correlation between location, age of housing, and risk of lead poisoning. Older, deteriorated housing is an indicator of poverty, and people 
living in these areas are a target population for service-based interventions by the Lead and Healthy Homes Program of the DPH. Updating the lead poisoning risk maps at different geographic scales allows the program to demonstrate to policy makers and community health practitioners the importance of lead poisoning prevention activities, to plan educational outreach to reduce exposures, and for soliciting new funding for prevention.

In addition to lead, the age of housing is also an indicator of risk for other home-based environmental health issues. The correlation between older, poorly maintained homes with lead paint hazards and other housing-related disease exposures, such as asthma, are due to the likelihood of general deterioration and lack of maintenance that leads to health-associated environmental triggers (Kreiger \& Higgins, 2002). GIS maps of housing age and location are useful in developing interventions for these other housingrelated diseases and can lead to synergy between various public health prevention programs.

Spatial maps are useful in identifying priority areas for public health prevention efforts. They enhance traditional methods of lead poisoning prevention activities by visually highlighting at-risk communities, in which health care providers live and work, and can be used to encourage more blood lead testing of high-risk children and education on reducing housing risk. With these improved maps, the Lead and Healthy Homes program of the DPH can plan for reducing the burden of lead poisoning in Georgia. As Public Health agencies are faced with limited funds for prevention, utilizing tools that can target public health interventions to high-risk children in the state will result in long-term cost savings and improved health outcomes.

Acknowledgements: The authors would like to thank all the public health practitioners working each day to prevent childhood lead poisoning. This article was supported in part by Cooperative Agreement Number, 5UE1 EH001258-02, funded by the Centers for Disease Control and Prevention. Its content are solely the responsibility of the authors and do not necessarily represent the official views of the Centers for Disease Control and Prevention or the Department of Health and Human Services.

\section{References}

Bell, B., Hoskins, R., Pickle, L., Wartenberg, D. (2006). Current practices in spatial analysis of cancer data: Mapping health statistics to inform policymakers and the public. International Journal of Health Geographics, 5(49), Retrieved from http://www.ncbi.nlm.nih.gov/pmc/articles/PMC1647272/

Binns, H. J., Cambell, C., \& Brown, M. J. (2007). Interpreting and managing blood lead levels of less than $10 \mu \mathrm{g} / \mathrm{dL}$ in children and reducing childhood exposure to lead: Recommendations of the Centers for Disease Control and Prevention Advisory Committee on childhood lead poisoning prevention. Pediatrics, 120(5), e1285-e1298.

Canfield, R.L., Henderson, C.R., Cory-Slechta, D.A., Cox, C., Jusko, T.A., \& Lanphear, B.P. (2003). Intellectual impairment in

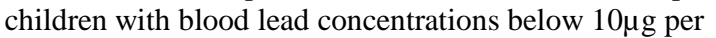
deciliter. The New England Journal of Medicine, 348(16), 15171526.

Centers for Disease Contrl and Prevention (CDC). (2015). Lead. Retrieved from http://www.cdc.gov/nceh/lead/
Centers for Disease Control and Prevention (CDC). (2012a). Prevention Tips. Retrieved from http://www.cdc.gov/nceh/lead/tips.htm

Centers for Disease Control and Prevention (CDC). (2012b). Recommendations in "Low Level Lead Exposure Harms Children: A Renewed Call of Primary Prevention” Retrieved from http://www.cdc.gov/nceh/lead/

Centers for Disease Control and Prevention (CDC). (2008). About the childhood lead poisoning prevention program. Retrieved from http://www.cdc.gov/nceh/lead/about/program.htm

Centers for Disease Control and Prevention (CDC). (2000) Eliminating childhood lead poisoning: A federal strategy targeting lead paint hazards. Retrieved from http://www.cdc.gov/nceh/lead/about/fedstrategy2000.pdf

Centers for Disease Control and Prevention (CDC). (1998). Lead poisoning associated with imported candy and powdered food coloring-California and Michigan. Morbidity and Mortality Weekly Reports, 47(48), 1041-1043. Retrieved from http://www.cdc.gov/mmwr/preview/mmwrhtml/00055939.htm

Dignam, T.A, Evens, A., Eduardo, E., Ramirez, S.M., Caldwell, K.L., Kilpatrick, N., Noonan, G.P., Flanders, W.P., Meyer, P.A., \& McGeehin, M.A. (2003). High-Intensity targeted screening for elevated blood lead levels among children in 2 inner-city Chicago communities. American Journal of Public Health, 94(11), 1945-1951.

Farr, N. \& Dolbeare, C.N. (1996). Childhood lead poisoning: Solving a health and housing problem. Cityscape, 2(3), 167-181.

Georgia Department of Public Health (DPH). (2015). Healthy Homes and Lead Poisoning Prevention. Retrieved from http://dph.georgia.gov/healthy-homes-and-lead-poisoningprevention

Hopfer, S., Chadwick, A., Parrot, R., Ghetian, C. \& Lengerich, E. (2008). Assessment of training needs and preferences for geographic information systems (GIS) mapping in state comprehensive cancer-control programs. Health Promotion and Practice [online], Retrieved from http://hpp.sagepub.com/content/10/4/579.short

Jacobs, D.E., Clickner, R.P., Zhou, J.Y., Viet, S.M., Marker, D.A., Rogers, J.W., Zeldin, D.C., Broene, P. \& Friedman, W. (2002)., The prevalence of lead-based paint hazards in U.S. housing. Environmental Health Perspectives, 110(10), 599-606.

Jerritt, M., Gale, S. \& Kontgis, C. (2010). Spatial modeling in environmental and public health research. International Journal of Environmental Research and Public Health, 7, 1302-1329.

Krieger, J. \& Higgins, D.L. (2002). Housing and health: Time again for public health action. American Journal of Public Health, 92(5), 758-768.

Koller, K., Brown, T., Spurgeon, A., Levy, L. (2004). Recent developments in low-level lead exposure and intellectual impairment in children. Environmental Health Perspectives. 112(9), 987-994.

Kurland, K.S. \& Wilpen, G.L. (2009). GIS tutorial for health. Third edition. Redlands, CA: ESRI Press.

Lanphear, B.P., Hornung, R. \& Ho, M. (2005). Screening housing to prevent lead toxicity in children. Public Health Reports, 120, 305-310, Retrieved from http://www.ncbi.nlm.nih.gov/pmc/articles/PMC1497723/pdf/16 134573.pdf

Landrigan, P.J., Rauh, V.A. \& Galvez, M.P. (2010). Environmental justice and the health of children. Mount Sinai Journal of Medicine, 77, 178-187.

Markowitz, G. \& Rosner, D. (2000). “Cater to the children”: The role of the lead industry in a public health tragedy, 1900-1955. American Journal of Public Health, 90(1), 36-46.

Miranda, M.L., Maxson, P. \& Kim, D. (2010). Early childhood lead exposure and exceptionality designations for students. International Journal of Child Health and Human Development, 3(1), 77-84. 
Miranda, M.L., Kim, D., Galeano, M.A., Paul, C.J., Hull, A.P. \& Morgan, S.P. (2007). The relationship between early childhood blood lead levels and performance on end-of-grade tests. Environmental Health Perspectives, 115(8), 1242-1247.

Needleman, H. L., McFarland, C., Ness, R. B., Fienberg, S. E., \& Tobin, M. J. (2002). Bone lead levels in adjudicated delinquents. A case control study. Neurotoxicology Teratology, 24, 711-717.

Peng, Z. (2001). Internet GIS for public participation.

Environmental and Planning B: Planning and Design, 28, 889905.
Rabin, R. (1989). Warnings unheeded: A history of child lead poisoning. American Journal of Public Health, 79(12), 16681674.

Rauh, V.A., Landrigan, P.J. \& Claudio, L. (2008). Housing and health: Intersection of poverty and environmental exposures. Annals of the New York Academy of Sciences, 1136(1), 276288.

United States Census Bureau (2013). American Community Survey 2009-2013. Retrieved from http://factfinder.census.gov/faces/tableservices/jsf/pages/product view.xhtml?src $=$ bkmk 